\title{
Role of Interleukin 6 and Tumor Necrosis Factor Alpha in Determination of Skin Wound Age in Human Cadavers: Histopathological and Immunohistochemical Study
}

\author{
Eman Salah El-Din El-Zahed ${ }^{1}$, Abdalaziz M. A. Othman ${ }^{1,3}$, Samah Mohamed Ahmed $^{2}$, Eman \\ Ahmed Alaa El-Din ${ }^{1}$ \\ Forensic Medicine and Clinical Toxicology ${ }^{1}$, Histology and Cell Biology ${ }^{2}$ Departments. Faculty of \\ Medicine-Zagazig University, Zagazig, Egypt and Judicial Experience and Research Center ${ }^{3}$, \\ Aljabal Alakhdar, Libya
}

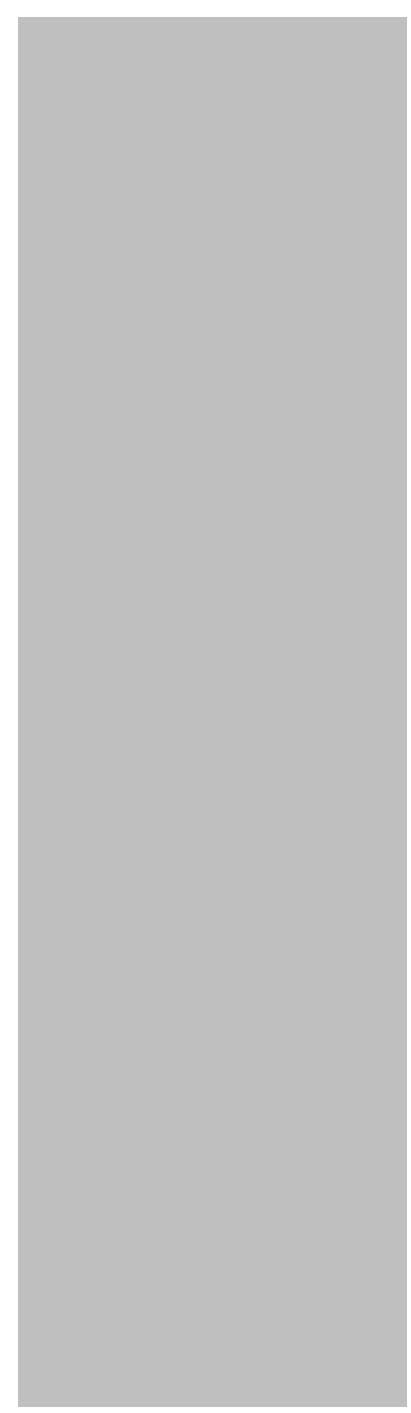

\section{ABSTRACT}

Estimation of wound age is of at most importance in medicolegal death cases. Wound age can be evaluated using morphological, cytological, and molecular biological techniques. The purpose of this study was to evaluate the role of interleukin-6 (IL-6) and tumor necrosis factor-alpha (TNF- $\alpha$ ) in the determination of wound age in autopsy cases. The present study included (20) autopsy cases; (16) with chronologically dated stab wounds (wound age varied from 30 to 300 minutes) and (4) cases without any injury to provide skin specimens serving as a negative control (Control group). Injured cases were examined, full-thickness skin specimens were collected and classified chronologically according to age of wound into 4 groups each group consisted of 4 specimens: Group I: (Time of injury $\leq 30 \mathrm{~min}$ ), Group II: (Time of injury 31-60 min), Group III: (Time of injury 61-120 min), Group IV: (Time of injury $>120 \mathrm{~min}$ ). Each group of injured cases was divided into two subgroups: Subgroup A: At uninjured contralateral site, Subgroup B: At the site of injury. All specimens were stained and studied and subjected to histological, immunohistochemical followed by a histomorphometric. The times passed since injury infliction (stab wound) caused a change in the area percentage of the released cytokines (TNF- $\alpha$ and IL6) whereas, early detection of (TNF- $\alpha$ and IL6) were at $30 \mathrm{~min}$ and a marked reaction became obvious at 31-60 min and from $30 \mathrm{~min}$ to $300 \mathrm{~min}$, there was a significant and progressive time-dependent increase in the area percentage of the two markers, evaluated semi-quantitatively. We concluded that proinflammatory cytokines (IL-6) and (TNF- $\alpha$ ) could serve as a useful tool for the estimation of wound age, in particular in the early post-traumatic interval prior to leukocyte reaction.

Keywords:

Wound age, cytokine, immunohistochemistry, interleukin-6, tumor necrosis factor-alpha

\section{I- INTRODUCTION}

D etermining the age of a wound is challenging in forensic pathology, but it can contribute to the reconstruction of crime scenes and lead to arrest of the suspects. Forensic scholars have tended to focus on evaluating wound age and determining the time elapsed since the wound was sustained.
Recent progress in forensic techniques has enabled the evaluation of the wound at the cellular and molecular levels, as well as simultaneous assessment of multiple markers (Na et al., 2018).

Histochemical studies have been conducted in this area over the last 25 years. Recently, immunohistochemical methods have mostly 
become the focus of studies on wound healing. Skin wound has been studied based (2018) mentioned that, autopsy specimens are the most accurate and realistic samples, particularly if the wound age is known.

Following injury, platelet aggregation is initiated when platelets released from injured blood vessels come into contact with subendothelial collagen, which sets off the coagulation mechanism. The platelet coagulation resulting from this contact and thrombin and fibronectin that are already present in the environment lead to the release of cytokines from alpha granules of platelets (Betz, 1994).

Cytokines may, therefore, play an important role in wound healing, especially, interleukin 6 (IL-6) and tumor necrosis factor (TNF)- $\alpha$ play an important role in the promotion of inflammatory reactions mainly contribute to the formation of granulation tissue and angiogenesis (O'Neill and Bowie, 2001).

In forensic pathology, the expression of these biological substances in skin wounds was applied to wound age determination while, in the consistent of the forensic autopsies, several immunohistochemical markers were applied to determine wound age more precisely, in addition to more traditional histological characteristics of wound healing (Kondo et al., 2000).

It is widely believed, that there are no established parameters or methods that yield accurate data about wound age estimation because of the non-specificity, poor repeatability, and inadequate diagnostic performance of biomarkers and the limitations of the techniques used ( Birincioglu et al., 2016).

Therefore, systematic and precise criteria are required to recognize valuable markers, and more advanced techniques to produce data with better accuracy and objectivity should be applied. Because wound-age estimation is a complicated and multifactorial problem thus, the use of a combination of several parameters could reduce the errors in woundage estimation (Fronczek et al., 2015). on experiments on animals and autopsy cases (Birincioglu et al., 2016). However, Na et al. The present study aimed to evaluate wound age in autopsy cases through detection of the activity of (IL6 and TNF- $\alpha$ ) semiquantitatively at the site of the wound and timing of the injury was correlated to the area percentage of IL6 and TNF- $\alpha$. This was detected by histopathological and immunohistochemical examination using the light microscope followed by histomorphometric study and image analysis.

\section{II- SUBJECTS AND METHODS}

\section{A- Subjects}

The study was carried out on 16 injured ( 3 females and 13 males) and (4) uninjured forensic autopsy cases that were admitted to Judicial Experience and Research Center, Aljabal Alakhdar, Omar El-Mokhtar University, Libya, from June 2018 to 2019. The protocol of this study was evaluated and approved by the Institutional Review Board (IRB) of the Faculty of Medicine, Zagazig University. Forensic autopsies were done on the direct request of the prosecutors. First of all, written consent was taken from the relatives of the first or second degree of the deceased to be enrolled in the present study. Inclusion criteria: Autopsy cases of both sexes, with age, ranged between 18 years to 50 years, having stab wounds of known age ranging from (30 to $300 \mathrm{~min}$ ) before death and mean time of gathering skin wound ranging from ( $3 \mathrm{hr}$ to $48 \mathrm{hr}$ ) postmortem. Exclusion criteria: Cases had any wound rather than stab, with known immunodeficiencies or Immunotherapy (severe malnutrition, malignant diseases or metabolic disorders, or have a history of medication such as cytostatic agents or glucocorticoids).

\section{Study design}

Subjects were divided into five groups as following:

Control group: Skin samples were taken from four autopsy cases without any injuries which served as negative control according to Grellner and Madea (2007). 
The injured autopsy cases were divided into four groups chronologically dated:

$(\mathrm{N}=4)$.

Group I: (Time of injury $\leq 30 \mathrm{~min}$ )

Group II: (Time of injury 31-60 min) $(\mathrm{N}=4)$. $\min )(\mathrm{N}=4)$.

Group III: (Time of injury 61-120

Group IV: (Time of injury> 120min) $(\mathrm{N}=4)$.

These groups were divided into two subgroups: Subgroup $\boldsymbol{A}$ : away from the site of injury Subgroup B: at the site of injury.

\section{B- Methods}

Full-thickness tissue specimens were collected according to the method of Grellner (2002) as the following:

1-Skin tissue from autopsy cases without injuries

2- Skin tissue from injured wound sites (0.5$1 \mathrm{~cm}$ in length and $0.5 \mathrm{~cm}$ in width) obtained from dead bodies.

3-Skin tissue from uninjured areas was taken in each individual (Taken from the contralateral side of the wound in the corpus) obtained from the same person served as a positive control for comparative study.

The most prevailing part of skin wound came from abdominal then thoracic then extremities than the back.

\section{1- Histological study}

Specimens from skin tissue in all groups were fixed in $10 \%$ neutral buffered formalin and processed for preparation of paraffin sections for histological examination: hematoxylin and eosin (H\&E) for overall morphological study (Bancroft et al., 2013).

\section{2- Immunohistochemical study}

Immunohistochemical analysis of TNF- $\alpha$ protein and IL-6 was carried out using the avidin-biotin peroxidase complex (Dako company, Wiesentheid/Bavaria, Germany, Biotin Blocking System, CodeX0590) method following the manufacturer's instructions. Serial sections $(3-4 \mathrm{~mm})$ of paraffinembedded specimens were deparaf-finized on charged slides. The sections were incubated in $0.1 \%$ hydrogen peroxide for 10 min to block the endogenous peroxidase activity and then incubated with the primary antibody. The primary antibody used against $\mathrm{TNF}-\alpha$ protein was a the human monoclonal antibody (Ab1Golden, Lab Vision Clone 2D2; Santa Cruz Biotechnology Inc., Santa Cruz, California, USA. Cat.\#MS-52B83). A human monoclonal antibody against IL-6 (Ab-1, CloneQBEnd/10, Lab Vision Corporation Laboratories, CA 6521,USA, Cat. \#MS-363R7). The slides were then incubated with the secondary anti-mouse anti-body versal kits (Zymed laboratories) diluted 1:200 for 30 min. Negative control sections for TNF- $\alpha$ protein and IL-6 were treated with nonspecific immunoglobulin instead of specific antibody and stained with Mayer's hematoxylin (Ramos-Vara et al., 2008).

3- Histo-morphometric study and image analysis

The image analyzer computer system Leica Qwin 500 (LeicaLtd, Cambridge, UK) in the image analyzing unit of the Pathology department, Faculty of Dentistry, Cairo University, Cairo, Egypt, was used to evaluate the area $\%$ of positive immunereaction of TNF- $\alpha$ protein and IL-6 using the immunostained sections. These slides under immune-histochemical staining were assessed semi quantitatively in the skin layers, share of positive epidermal cells $(<10 \%, 10 \pm 25$, $25 \pm 50,>50 \%$ ). Reactivity degree of the other histological structures (corium, vessels, sweat glands, sub epidermal cells) was classified on a scale as weak positive, positive-moderately, positive-strongly positive. These measurements were obtained by total magnification $\times 400$ the area $\%$ of positive immunoreactions for TNF- $\alpha$ protein and IL- 6

(Karikoski, 2016).

\section{4-Statistical Analysis:}

For statistical analysis, statistical package for the Social Sciences (SPSS version 20.0) software for analysis was used. According to the type of data qualitative represent as number and percentage, quantitative continues group represented by mean $\pm \mathrm{SD}$, the following tests were used to test differences for significance. Association by chi square, agreement by Kappa. Differences 
between quantitative paired groups by paired $\mathrm{t}$, multiple by ANOVA, correlation by Pearson's correlation. P-value was set at $<0.05$ for significant results $\&<0.001$ for a high significant result (Gamst et al., 2008).

\section{III-RESULTS}

In all sixteen chronologically dated stab wound cases that were enrolled in the present study from June 2018 to 2019; their age ranged from 18 yrs to 49 yrs. sites of stab wounds distribution were documented by forensic sheet, the most prevailing sites for stab wounds distribution were abdominal $(25 \%)$ then thoracic $(18 \%)$ then back $(12.5 \%)$ then extremities $(6.3 \%)$ and head \& neck $(6.3 \%)$. Concerning the time of gathering wound specimens, it was ranged from $3 \mathrm{hr}$ to 24hr. Regarding the wounds number among groups the highest number of stab wounds was one wound in $(62.5 \%)$ followed by three wounds in $(18.3 \%)$ then two wounds in $(12.5 \%)$ and four wounds in $(6.3 \%)$. Median (Range) length of stab wounds was measured; median range $1.5(1 \mathrm{~cm}-4 \mathrm{~cm})$ (Fig.1).

\section{Histological result:}

Hematoxylin and eosin (H\&E) stained sections of the control group showed the normal histological structure of human thin skin. Also, skin sections of group I ( $\leq 30 \mathrm{~min})$ and group II (31-60 min); at the site of injury and away from the site of injury: showed no obvious changes and were almost near the control group. While group III (60-120 min); at the site of injury: showed cellular infiltration (PML) and normal skin layer was observed away from the site of injury and similar changes were detected in group IV (>120 min) (Fig.2).

\section{Immunohistochemical and Histo- morphometric results}

Results revealed significant changes in the staining pattern in vital wounds concerning epidermal layers, sub-epidermal cells, vessels, and sweat glands. interleukin-6 immunoreactions showed enhanced expression $\leq 30 \mathrm{~min}$ at the earliest release ( an increase of epidermal reactivity) and continued after $31 \pm 60 \mathrm{~min}, 60 \pm 120 \mathrm{~min}$. and $>120$ min. respectively, marked expression was observed at $31-60$ min. Similar alterations were detectable with tumor necrosis factor-alpha after $31 \pm 60 \mathrm{~min}$, 61 $\pm 120 \mathrm{~min}$. and >120min (Fig.3\&4).

The percentage area expression of (TNF- $\alpha$ and IL6) were significantly lower in the skin of the control group than in other groups. Whereas, group I $(\leq 30$ minutes $)$ showed significantly higher expression than control. While group II (31-60 minutes) showed significantly higher expression than control and group I. Also, highly statistically significant increase in the mean area percentage of TNF- $\alpha$ and IL-6 immunoreactions was detected in both groups III (61 -120 minutes) and IV (>120 minutes) as compared to (Control), groups I and II but there was no significant difference between the last two groups (Table 1).

When Comparing between injured and noninjured (subgroups) at each group, there was no significant difference in group $\leq 30$ minutes or 31-60 minutes groups but injured skin showed significantly higher area percentage of IL6 and TNF- $\alpha$ than noninjured skin in 61-120 and >120minutes groups (Table 2). The correlation coefficient showed statistically significant increased TNF- $\alpha$ and IL- 6 immunoreactions in relation to the time passed since injury (Fig. 5 \&6) (Table 3). Also, IL-6 sensitivity was $85.5 \%$ and specificity was $73.3 \%$ while, on the other hand, TNF-sensitivity was $83.3 \%$ and specificity was $60 \%$. So IL6 could be considered better than TNF- $\alpha$ as a marker for estimation of wound age (Fig. 7) (Table 4). 
Table (1): Comparison between different groups regarding area percentage of interlekin-6 and tumor necrosis factor alpha immunohistochemical expression.

\begin{tabular}{|c|c|c|c|c|c|c|}
\hline & & $\mathbf{N}$ & Mean & S. D & $\mathbf{F}$ & $\mathbf{P}$ \\
\hline \multirow{5}{*}{$\begin{array}{l}\text { Area percentage of IL6 } \\
\text { injured skin }\end{array}$} & Control & 4 & 4.7500 & .50000 & \multirow[t]{5}{*}{373.446} & \multirow[t]{5}{*}{$0.00 * *$} \\
\hline & $\leq 30$ Minutes & 4 & $\# 14.1000$ & 2.30940 & & \\
\hline & 3'-60 Minutes & 4 & $\& 25.5000$ & 1.73205 & & \\
\hline & 6)-120 Minutes & 4 & $* 50.7500$ & 3.30404 & & \\
\hline & >120Minutes & 4 & $* 53.0000$ & 2.44949 & & \\
\hline \multirow{5}{*}{$\begin{array}{c}\text { Area percentage of IL6 } \\
\text { normal skin }\end{array}$} & Control & 4 & 4.7500 & .50000 & \multirow[t]{5}{*}{389.730} & \multirow[t]{5}{*}{$0.00 * *$} \\
\hline & $\leq 30$ Minutes & 4 & $\# 14.0000$ & 1.15470 & & \\
\hline & 3)-60 Minutes & 4 & $\& 23.5000$ & 2.88675 & & \\
\hline & 6)-120 Minutes & 4 & *39.5000 & 1.29099 & & \\
\hline & >120Minutes & 4 & $* 40.2500$ & .95743 & & \\
\hline \multirow{5}{*}{$\begin{array}{l}\text { Area percentage of } \\
\text { TNF- } \alpha \text { in injured skin }\end{array}$} & Control & 4 & $\# 1.5000$ & .57735 & \multirow[t]{5}{*}{207.409} & \multirow[t]{5}{*}{$0.00 * *$} \\
\hline & $\leq 30$ Minutes & 4 & $\# 2.5000$ & .57735 & & \\
\hline & 3)-60 Minutes & 4 & $\& 4.7500$ & 1.50000 & & \\
\hline & 6)-120 Minutes & 4 & $* 30.2500$ & 3.40343 & & \\
\hline & >120Minutes & 4 & $* 33.7500$ & 3.20156 & & \\
\hline \multirow{5}{*}{$\begin{array}{l}\text { Area percentage of } \\
\text { TNF- } \alpha \text { normal skin }\end{array}$} & Control & 4 & $\# 1.5000$ & .57735 & \multirow[t]{5}{*}{ 233.093 } & \multirow[t]{5}{*}{$0.00 * *$} \\
\hline & $\leq 30$ Minutes & 4 & \#2.2500 & .50000 & & \\
\hline & 3)-60 Minutes & 4 & \&3.7500 & 1.50000 & & \\
\hline & 6)-120 Minutes & 4 & $* 18.5000$ & 1.29099 & & \\
\hline & >120Minutes & 4 & $* 18.7500$ & 1.50000 & & \\
\hline
\end{tabular}

SD: standard deviation.

$\mathrm{N}$ : number of cases.

$\mathrm{P}$ : significance. **: Highly significant $(\mathrm{P}<0.01)$

* Similar group with no significant between them

\# Similar group with no significant between them

$\&$ group different from all other groups

IL6: interlekin-6

TNF- $\alpha$ : tumor necrosis factor alpha 
Table (2): Comparison between all subgroups (injured and non-injured skin) at each group regarding area percentage of interlekin-6 and tumor necrosis factor alpha immunohistochemical expression.

\begin{tabular}{|c|c|c|c|c|c|}
\hline \multicolumn{2}{|r|}{ Group } & Mean & S. D & Paired t & $\mathbf{P}$ \\
\hline \multirow[t]{4}{*}{$\begin{array}{l}\text { Gp.(I) } \\
\leq 30 \text { Min }\end{array}$} & $\begin{array}{l}\text { Area percentage of IL6 } \\
\text { injured skin }\end{array}$ & 14.1000 & 2.30940 & $-1.732-$ & 0.182 \\
\hline & $\begin{array}{l}\text { Area percentage of IL6 } \\
\text { non-injured skin }\end{array}$ & 14.0000 & 1.15470 & & \\
\hline & Area percentage of TNF- $\alpha$ injured skin & 2.5000 & .57735 & 1.000 & 0.391 \\
\hline & $\begin{array}{l}\text { Area percentage of n TNF- } \alpha \text { non- } \\
\text { injured skin }\end{array}$ & 2.2500 & .50000 & & \\
\hline \multirow[t]{4}{*}{$\begin{array}{l}\text { Gp.(II) } \\
\text { 31-60 Min }\end{array}$} & $\begin{array}{c}\text { Area percentage of IL6 } \\
\text { injured skin }\end{array}$ & 25.5000 & 1.73205 & 2.000 & 0.139 \\
\hline & $\begin{array}{c}\text { Area percentage of IL6 } \\
\text { non-injured skin }\end{array}$ & 23.5000 & 2.88675 & & \\
\hline & Area percentage of TNF- $\alpha$ injured skin & 4.7500 & 1.50000 & 2.449 & 0.092 \\
\hline & $\begin{array}{l}\text { Area percentage of TNF- } \alpha \\
\text { non-injured skin }\end{array}$ & 3.7500 & 1.50000 & & \\
\hline \multirow[t]{4}{*}{$\begin{array}{c}\text { Gp.(III) } \\
\text { 61-120 Min }\end{array}$} & $\begin{array}{l}\text { Area percentage of IL6 } \\
\text { injured skin }\end{array}$ & 50.7500 & 3.30404 & 9.000 & $0.003 *$ \\
\hline & $\begin{array}{c}\text { Area percentage of IL6 in } \\
\text { non-injured skin }\end{array}$ & 39.5000 & 1.29099 & & \\
\hline & $\begin{array}{l}\text { Area percentage of n TNF- } \alpha \text { injured } \\
\text { skin }\end{array}$ & 30.2500 & 3.40343 & 8.182 & $0.004 *$ \\
\hline & $\begin{array}{l}\text { Area percentage of TNF- } \alpha \\
\text { non-injured skin }\end{array}$ & 18.5000 & 1.29099 & & \\
\hline \multirow{4}{*}{$\begin{array}{l}\text { Gp.(IV) } \\
>120 \mathrm{Min}\end{array}$} & Area percentage of IL6 injured skin & 53.0000 & 2.44949 & 9.696 & $0.002 *$ \\
\hline & Area percentage of IL6 non-injured skin & 40.2500 & .95743 & & \\
\hline & Area percentage of TNF- $\alpha$ injured skin & 33.7500 & 3.20156 & 7.348 & $0.005^{*}$ \\
\hline & $\begin{array}{l}\text { Area percentage of TNF- } \alpha \\
\text { non-injured skin }\end{array}$ & 18.7500 & 1.50000 & & \\
\hline
\end{tabular}

SD: standard deviation

Gp:group

TNF- $\alpha$ : tumor necrosis factor alpha IL6: interlekin-6

P: significance $(p<0.05$ significant $*) \quad(p<00.1$ highly significance $)$

Table (3): Correlation between area percentage of interlekin-6 and tumor necrosis factor alpha immunohistochemical expression with the time.

\begin{tabular}{|c|c|c|}
\hline & & Time between injury and death/Min \\
\hline \multirow[t]{2}{*}{ Area percentage of IL6 } & $\mathbf{r}$ & $0.852^{* * *}$ \\
\hline & $\mathbf{P}$ & 0.000 \\
\hline \multirow[t]{2}{*}{ Area percentage of TNF- $\alpha$} & $\mathbf{r}$ & $0.822^{* *}$ \\
\hline & $\mathbf{P}$ & 0.000 \\
\hline
\end{tabular}
r: Pearson's correlation coefficient
(**) significantly high
$\mathrm{P}$ : significance, ( $\mathrm{p} 0.00$ non significance)
IL6: interlekin-6
TNF- $\alpha$ : tumor necrosis factor alpha 
Table (4): Sensitivity and Specificity of the markers interlekin-6 and tumor necrosis factor alpha.

\begin{tabular}{|c|c|c|c|c|c|c|c|}
\hline \multirow[t]{2}{*}{$\begin{array}{l}\text { Test Result } \\
\text { Variable(s) }\end{array}$} & \multirow[t]{2}{*}{ Area } & \multirow[t]{2}{*}{$\begin{array}{l}\text { Cut } \\
\text { off }\end{array}$} & \multirow[t]{2}{*}{$\mathbf{P}$} & \multicolumn{2}{|c|}{$\begin{array}{l}\text { 95\% Confidence } \\
\text { Interval }\end{array}$} & \multirow[t]{2}{*}{ Sensitivity } & \multirow[t]{2}{*}{ Specificity } \\
\hline & & & & $\begin{array}{l}\text { Lower } \\
\text { Bound }\end{array}$ & $\begin{array}{l}\text { Upper } \\
\text { Bound }\end{array}$ & & \\
\hline $\begin{array}{c}\text { Area } \\
\text { percentage of } \\
\text { IL6 }\end{array}$ & 0.797 & $>45.5$ & $0.016 *$ & .564 & 1.000 & $85.5 \%$ & $73.3 \%$ \\
\hline $\begin{array}{c}\text { Area } \\
\text { percentage of } \\
\text { TNF- } \alpha\end{array}$ & 0.734 & $>24.7$ & $0.025 *$ & .485 & .984 & $83.3 \%$ & $60.0 \%$ \\
\hline
\end{tabular}

$P$ : significance $(\mathrm{p}<0.05$ significant $*)$

IL6: interlekin-6

TNF- $\alpha$ : tumor necrosis factor alpha
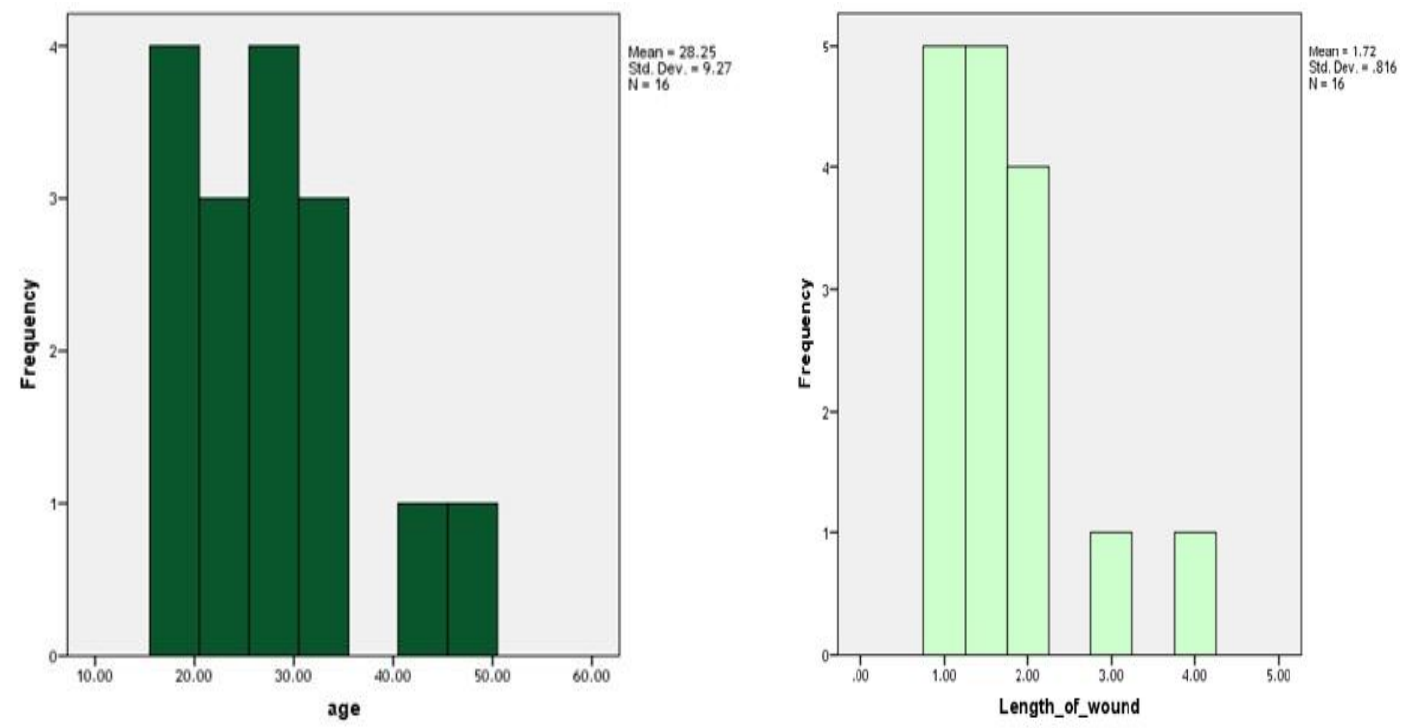


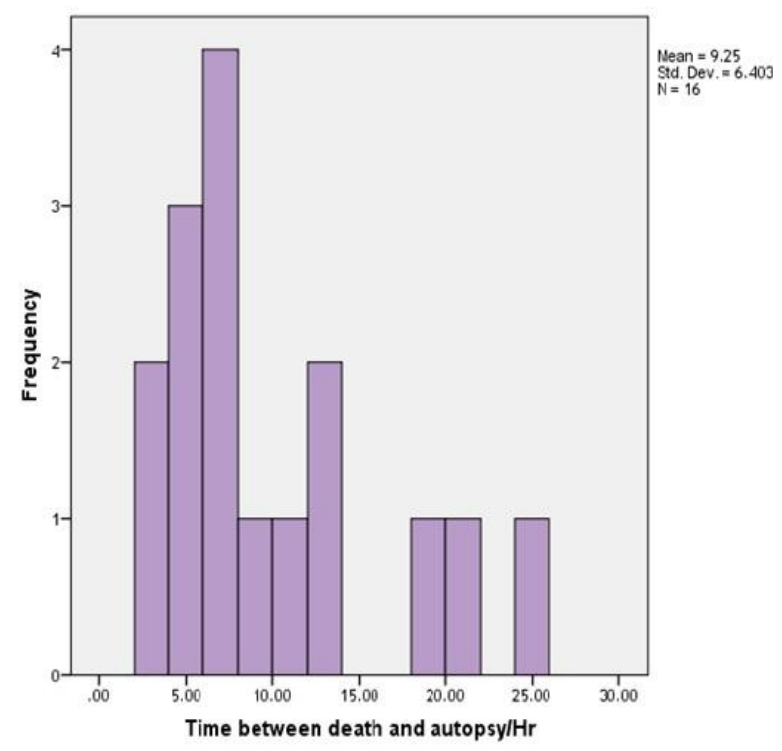

Figure (1) Graphs showing: Age distribution among the injured groups as $28.25 \pm 9.27$, Length of stab wounds distribution among injured groups as $1.71 \pm 0.58$, Distribution of time between death and autopsy/hr. as $9.25 \pm 5.9$ with a minimum $3 \mathrm{hrs}$.and a maximum $24 \mathrm{hrs}$.

SD: standard deviation.

$\mathrm{N}$ : number of cases
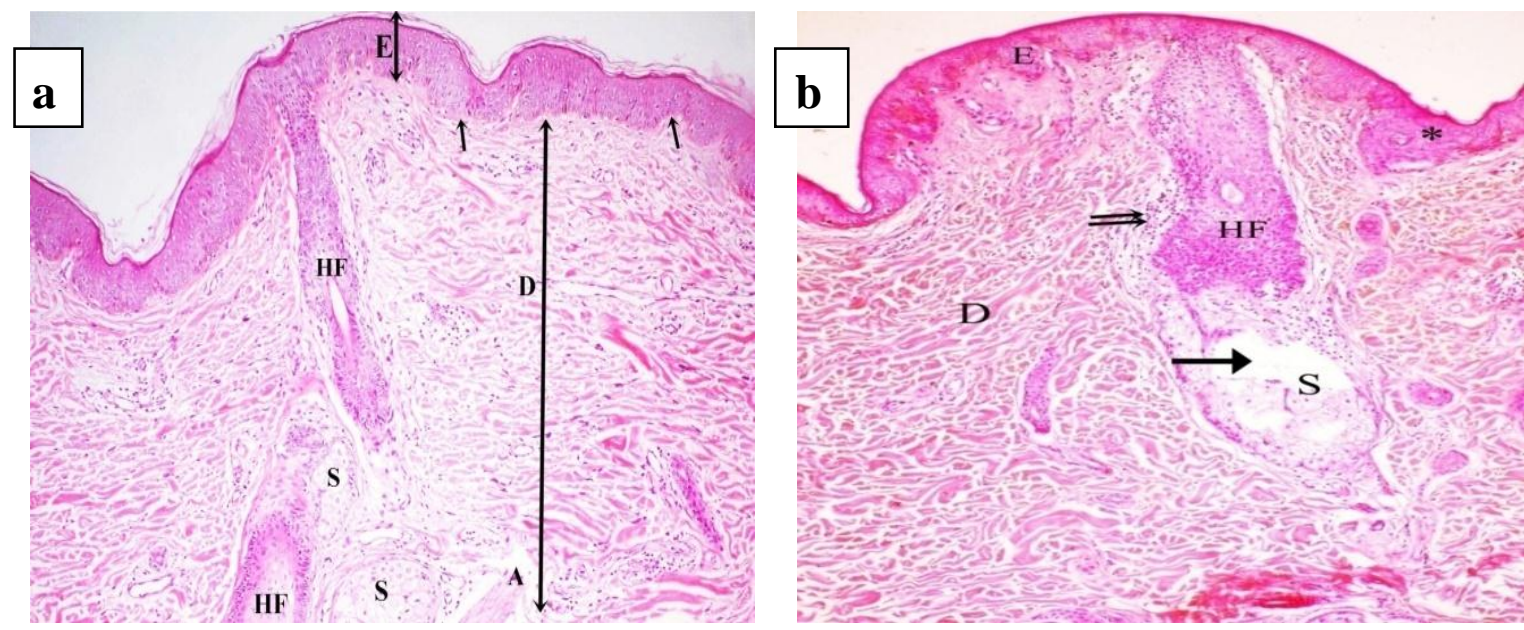


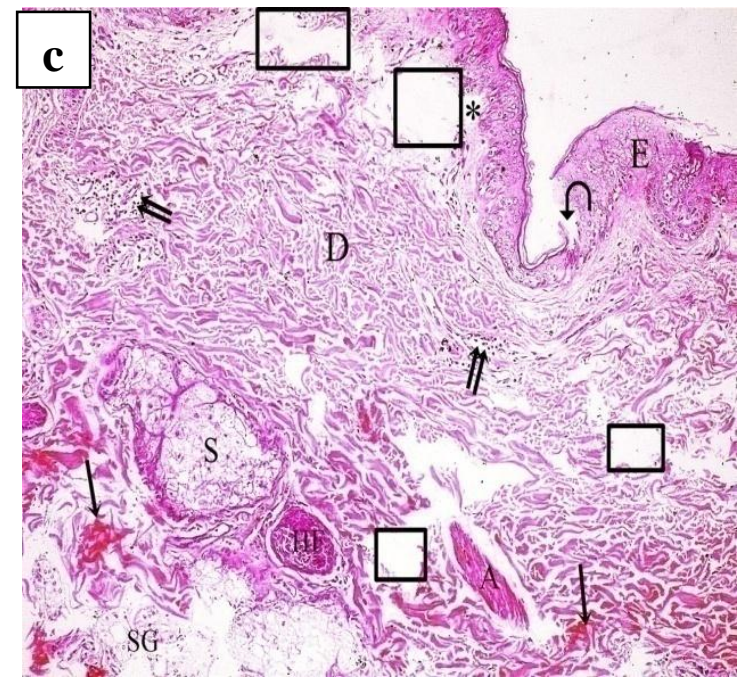

Figure (2): Photomicrographs of H\&E stained sections of human skin $(\mathrm{H} \& \mathrm{E} \times 100)$ : aControl group showing normal texture consisting of epidermis (E) and dermis (D).Dermo-epidermal junction (arrow) is noticed. Dermis contains hair follicles (HF) sebaceous glands(S) and errectorpili muscle (A). b- Subgroup 3B showing Epidermis(E) with epithelial disorganized keratinocytes (*) Hair follicle (HF) is associated will cellular infiltration(double arrow) in dermis(D),sweat gland (SG)\&sebaceous glands (S) were detected with some cellular loss (arrow). c- Subgroup 4B showing disrupted epithelium (curved arrow) lining epidermis(E).Separation $(*)$ between dermis(D) and epidermis, areas of connective tissue loss ( $\square$ ) in dermis, hyalinization (arrow) and cellular infiltration(double arrow) were noticed. Hair follicle (HF), sweat gland (SG) sebaceous gland (S) and arrectorpili muscles were detected.
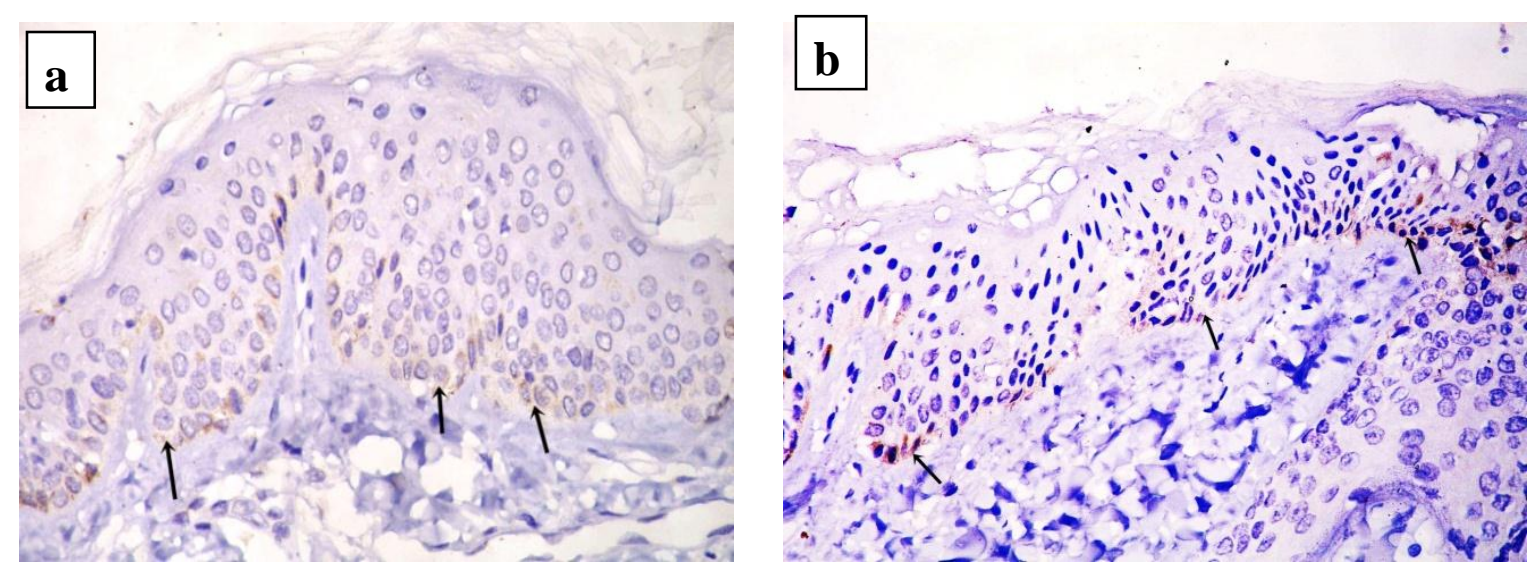

d 

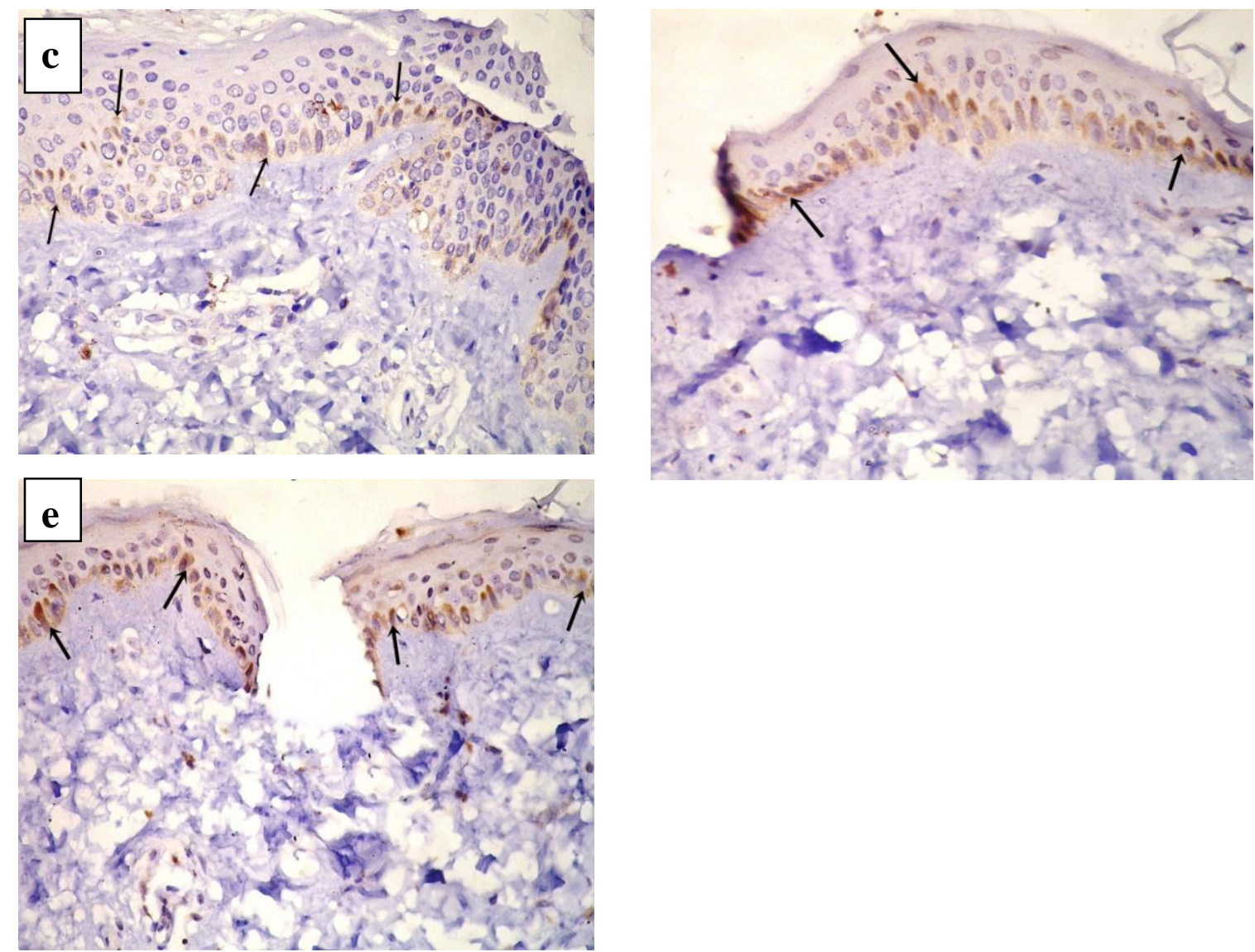

Figure (3): Photomicrographs of immunohistochemical reaction for TNF- $\alpha$ in the skin (Immunoperoxidase technique $\times 400$ ): a-Control group showed very weak positive reaction in the cytoplasm of few keratinocytes (arrow) b- Subgroup 1B TNF- $\alpha$ showed moderate positive reaction in the cytoplasm of few keratinocytes (arrow). c- Subgroup 2B TNF- $\alpha$ showed moderate positive immunoreaction in cytoplasm of some keratinocytes (arrow). d- Subgroup 3B TNF- $\alpha$ and e- Subgroup 4B TNF- $\alpha$ showed strong positive immunoreaction in cytoplasm of some keratinocytes (arrow).
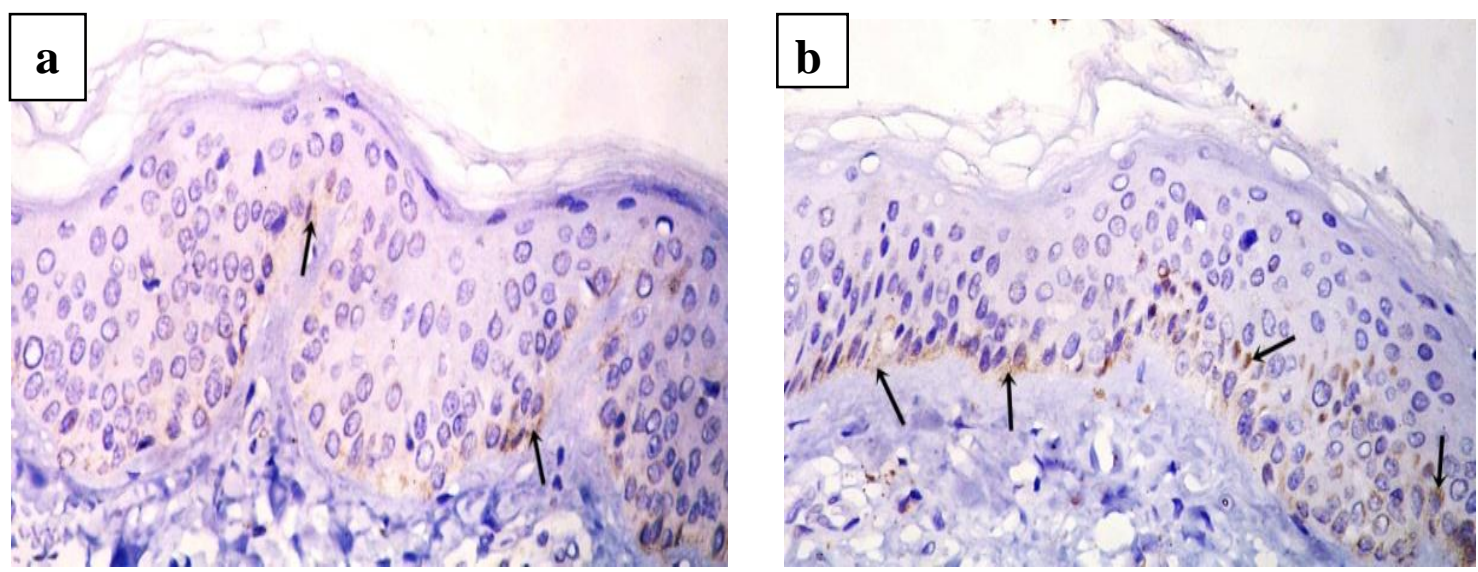

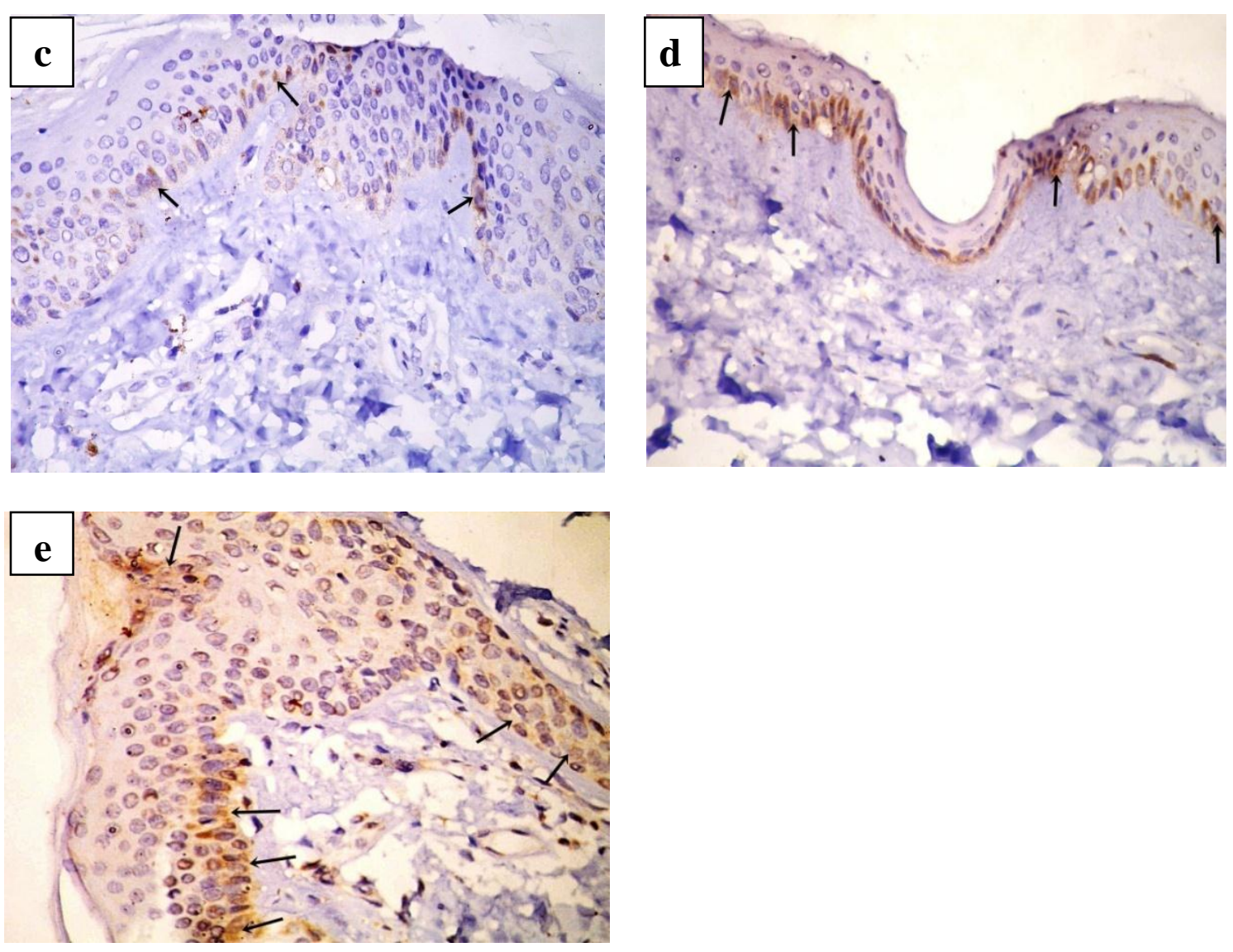

Figure (4): Photomicrographs of immunohistochemical reaction for IL-6 in the skin (Immunoperoxidase technique $\times 400$ ). : a- Control group showing weak positive immunoreaction in the cytoplasm of few keratinocytes (arrow) b-Subgroup 1B IL-6 showing moderate positive reaction in the cytoplasm of few keratinocytes (arrow). cSubgroup 2B IL-6 showing moderate positive immunoreaction in cytoplasm of some keratinocytes (arrow) d- Subgroup 3B IL-6 and e-Subgroup 4B IL-6 showing strong positive immunoreaction in cytoplasm of some keratinocytes (arrow). 


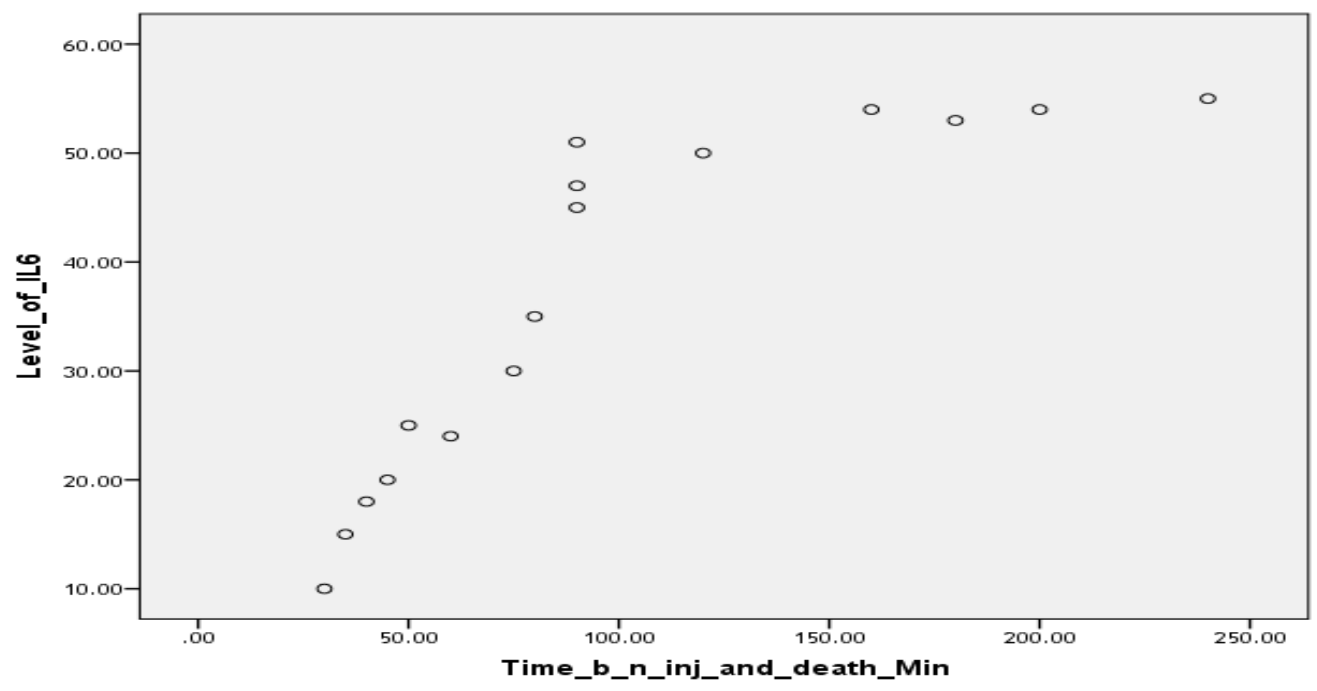

Figure (5): Graph showing positive correlation (significant increase) between interlekin-6 (IL6) area percentage and time.

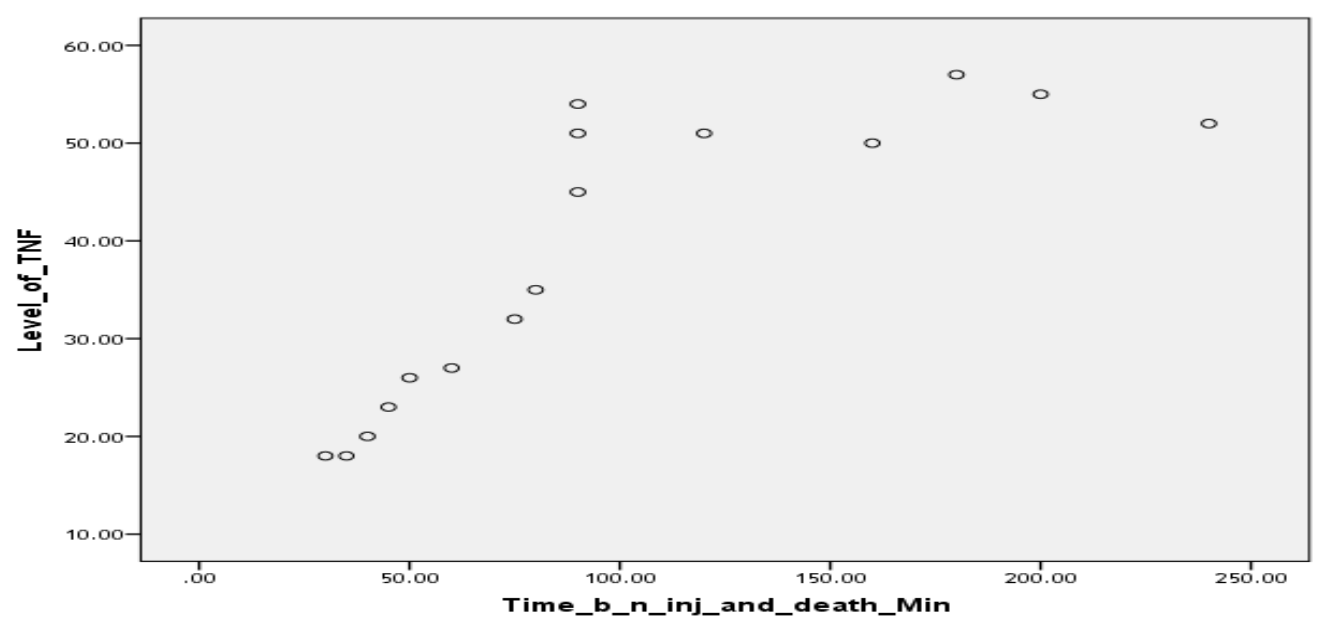

Figure (6) :Graph showing positive correlation (significant increase) between tumor necrosis factor alpha (TNF- $\alpha$ ) area percentage and time.

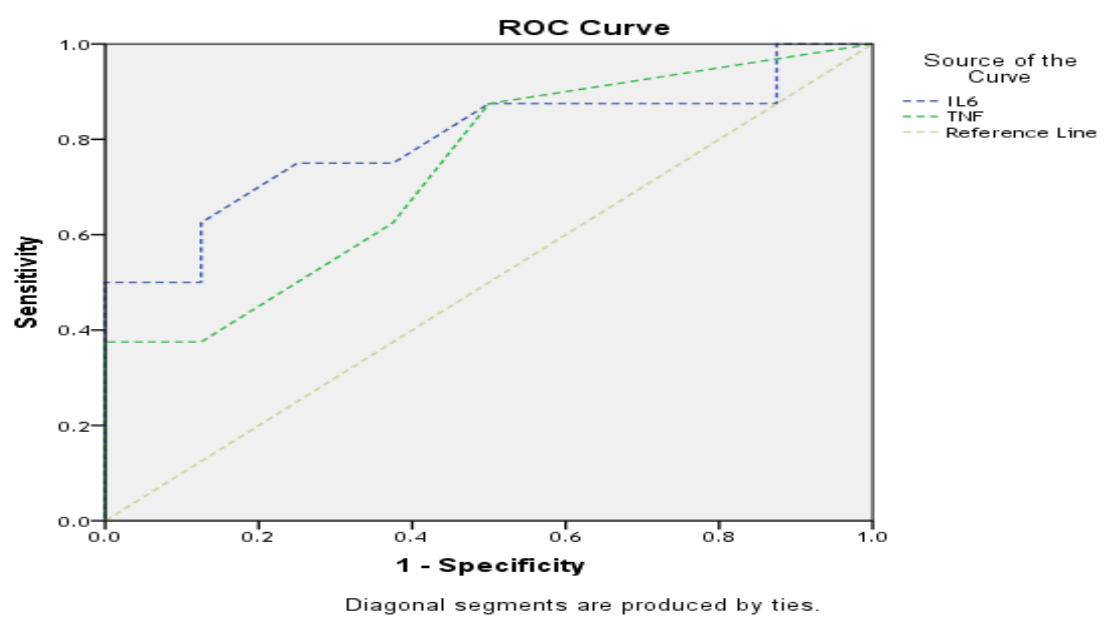

Figure (7): Graph demonstrated (ROC Curve) for wounded skin showing interlekin-6 (IL6) marker better than between tumor necrosis factor alpha (TNF- $\alpha$ ) marker in estimation of wound age time. 


\section{IV-DISCUSSION}

The evaluation of wound vitality or wound age is a classic but still modern theme in forensic pathology. It is particularly required in open wounds such as stab wounds (Oehmichen, 2004). The process of wound healing is very important in the practice of forensic medicine with its great medico legal significance in crimes, through understanding a wound characters and estimating its age, also, the wound can be determined if it is ante-mortem or post-mortem (Abbas et al., 2019).

For this purpose, the pathophysiology of skin wound healing should be understood thoroughly. Generally, skin wound healing process is composed of three different phases like inflammatory, proliferative and maturation phases. In each phase, various kinds of biological substances are closely involved. Examination of the dynamics of such biological substances becomes a clue to find an available marker for wound vitality or wound age (Ohshima, 2000).

Mimasaka (2002) and Gauchotte et al. (2013), considered that the immunohistochemical study is one of the most useful and widely used techniques for wound age determination, and proved that they could be used as markers for early-stage wounds age determination. So, the current study had attempted to assess the role of cytokines (IL-6 and TNF- $\alpha$ ) in identifying the age of injury, during the acute inflammatory phase.

The histological result of the present study showed no significant difference concerning wound age determination the only detected change was cellular infiltration in group III (61-120min) while other changes need further time reach up to $6 \mathrm{hr}$. This result could be explained by $\mathbf{Y u}$ et al. (2014) who discussed the chronological histopathological alterations that characterize the different phases of wound healing and their application in wound age determination. Neutrophils are initially recruited at the injury site, followed by macrophages, according to the post infliction interval. The cellular repair reaction is particularly dependent on the extent of the injury time.

Although conventional histological evaluation (e.g. with hematoxylin-eosin) can detect changes $6 \mathrm{~h}$ after an injury, its practical application is restricted, especially when the time of the study is limited. Whereas, immunohistochemistry studies are more useful and allowing localization of tissue factors indicative of the stage of response and determination of the phases of activation of individual cells (Cecchi , 2010) .

Immunohistochemical results of the present study revealed that (TNF- $\alpha$ and IL6) were weakly expressed in normal human skin constitutively and the times passed since the infliction of stab wound caused a significant change in the area percentage of (TNF- $\alpha$ and IL6). The staining pattern changed significantly in vital wounds concerning epidermal layers, sub-epidermal cells, vessels, and sweat glands. The earliest expression of (TNF- $\alpha$ - IL6) was detected $\leq 30$ min (an increase of epidermal reactivity) while the expression peaked at 31-60 min and enhanced expression persisted in $60 \pm 120 \mathrm{~min}$. and $>120$ min. groups. These results determined the time of early expression of cytokine in stab wound; the earliest estimation was at $30 \mathrm{~min}$ and the peak reached after $60 \mathrm{~min}$.

In line with the results of the present study, Birincioglu et al. (2016) found that IL-6 and TNF- $\alpha$ were weakly expressed in normal human skin, however, the staining pattern changed significantly in vital wounds concerning epidermal layers, sub-epidermal cells, vessels, and sweat glands and showed enhanced expression after $\leq 30 \mathrm{~min}$ at the earliest increase of epidermal reactivity and after 30min, IL-6 and TNF- $\alpha$ marked expression was observed, persisted over several hours and concluded that proinflammatory cytokines can serve as a useful tool for the estimation of vitality and wound age, in particular in the early posttraumatic interval prior to leukocyte reaction. 
Also, the results of the present study detected a statistically significant increase of the TNF$\alpha$ and IL- 6 immunoreactions in relation to the time of injury. Also, the interleukin- 6 sensitivity was $85.5 \%$ and specificity was $73.3 \%$ while, tumor necrotic factor TNF- $\alpha$ sensitivity was $83.3 \%$ and specificity was $60 \%$. So, IL6 is considered better than TNF- $\alpha$ in the estimation of wound age. Similar findings were observed by Grellner (2002).

Furthermore, Sun et al. (2019) reported that a nonspecific or unstable marker could not provide statistical safety, which hinders its use as evidence in forensic medicine. For specificity, it is necessary to confirm that the marker is negative in peripheral areas or contralateral uninjured specimens taken from the same individual, such as IL-6. For stability, a proper marker should not display evident denaturation and remain stable in post-mortem samples. Several markers considered to be promising were later on invalidated owing to post-mortem falsepositive results.

When comparing the results of the present study and the results of the other previous studies, marked graduation of the cytokine reactivity was noticed. As many factors influencing age determination of skin wounds (e.g circumstances of death, preexisting disease, previous medication, postmortem period, different autopsy and examination techniques) were described by Dettmeyer (2018). However, the final result will always be mathematical to obtain the best result in this field of forensic pathology, despite the technique and causes of induction the wound, but in each case, immunohistochemical methods granted the best result in forensic practice.

\section{V- CONCLUSIONS}

Regarding the aforementioned results, the following can be concluded: proinflammatory cytokines Tumor necrosis factor-alpha (TNF- $\alpha$ ) and Interleukin 6 (IL6) may play an important role in the wound healing process. They are very important chemical mediators in the acute inflammatory reaction as confirmed by their time-dependent up-regulation at the injury sites, suggesting that they could become useful markers for wound age determination.

\section{VI- RECOMMENDATIONS}

Further studies are required to investigate wound age using a larger size of human samples and to investigate the involvement of different organs and factors that affect cytokine release in tissue. Also, it is recommended to use other types of inflammatory mediators and cytokines to study the pattern of cytokine release during sequential time intervals and to find a more precise way for wound age estimation.

\section{Declaration of interest}

The authors declare that they have no conflict of interest.

\section{Funding information}

This study was not funded by any source.

\section{REFERENCE}

1. Abbas S., Mahmoud S.M., Helmi A.R., Elhady K.A. (2019): Considering Heal Promoters in Estimating Wound Age in Rats. European Journal of Scientific Exploration. 2(2):1-17.

2. Bancroft, J.D., Layton, C. and Suvarna, S.K., (2013): Bancroft's theory and practice of histological techniques. $7^{\text {th }}$ ed., Philadelphia: Churchill, Livingstone of El Sevier, pp 386431.

3. Betz P.(1994): Histological And Enzyme Histochemical Parameters For The Age Estimation Of Human Skin Wounds. In I.J.L med., 107(2):60-8.

4. Birincioglu I., Akbaba M., Alver A., SevalKul C., Nurs E., Turan E., Ays S.,Entürk C. and Ince I. (2016): Determination of skin wound age by using cytokines as potential markers. Journal of Forensic and Legal Medicine, 44:14-19.

5. Cecchi R. (2010): Estimating wound age: looking into the future. Int $\mathrm{J}$ Legal Med. ,124:523-536.

6. Dettmeyer R. (2018): Vitality, Injury Age, Determination of Skin Wound Age, and Fracture Age. In: Forensic Histopathology, University Hospital Giessen Institute of Forensic Medicine, Giessen, Germany. pp 241-263. 
7. Fronczek J., Lulf R., H. Korkmaza I. , Birgit I. , Franklin R.W., Begienemana M. , Krijnena P., Rozendaal L., Niessena H. and Reijnders U. (2015): Analysis of morphological characteristics and expression levels of extracellular matrix proteins in skin wounds to determine wound age in living subjects in forensic. Forensic Science International, 246: 86-91.

8. Gamst G., Meyers L. S. and Guarino, A. J. (2008): Analysis of variance designs: A conceptual and computational approach with SPSS and SAS. Cambridge University Press.

9. Gauchotte G., Martrille L., Plenat F. and Vignaud J.M. (2013): The markers of wound vitality in forensic pathology. In Annales de pathologie 33(2): 93-101.

10. Grellner W. (2002): Time-dependent immunohistochemical detection proinflammatory cytokines in human skin wounds. Forensic science international journal, 13: 90-96.

11. Grellner W. and Madea B. ( 2007): Demands on scientific studies: vitality of wounds and wound age estimation. Forensic Sci Int., 165:150-154.

12. Karikoski, N.(2016): The Prevalence and Histopathology of Endocrinopathic Laminitis in Horses.

13. Kondo T., Ohshima T., Mori R., Guan D. W., Ohshima K. and Eisenmenger W. (2002): Immunohistochemical detection of chemokines in human skin wounds and its application to wound age determination. International journal of legal medicine, 116(2): 87.

14. Mimasaka S. (2002): Postmortem cytokine levels and the cause of death. Tohoku J Exp Med, 197: 145-50.

15. Na L., Qiuxiang D, Rufeng B. and Junhong S. (2018): Vitality and wound-age estimation in forensic pathology: review and future prospects. Forensic Sciences Research, 165(23): 1-10.

16. Oehmichen, M., 2004. Vitality and time course of wounds. Forensic science international, 144(2-3):221-231
17. Ohshima T. (2000): Forensic wound examination, Forensic Science International. 113 (1-3):153-164.

18. O'Neill L.A.J. and Bowie A.( 2001): Interleukin protocols. Methods in molecular medicine series, Volume 60. New York, Springer, 60:3-15.

19. Ramos-Vara, J. A., Kiupel, M., Baszler, T., Bliven, L., Brodersen, B., Chelack, B. and Graham, T. (2008): American association of veterinary laboratory diagnosticians subcommittee on standardization of immunohistochemistry suggested guidelines for immunohistochemical techniques in veterinary diagnostic laboratories. J Vet Diagn Invest, 20(4):393-413.

20. Sun J.H., Zhu X.Y., Li S.Q., Dong T.N. and Du Q.X. (2019): Measuring temporal expression, systematic response, and postmortem stability to assess potential markers for estimating wound age: an example of Fosl1 in contused skeletal muscle. Australian Journal of Forensic Sciences, 51(2):158-170.

21. Yu T.S., Guan W.D. and Zhao R. (2014): Correlation between Percentages of PMN, MNC, FBC and wound age after skeletal muscle injury in rats. Fa Yi XueZaZhi., 30(3):166-168. 


\section{دور الإنترلوكين - 1 و وعامل نخر الورمي ـ الفا في تحديد عمر جرح الجلد في الجثث البشرية: دراسة الأنسجة المرضية و كيمياء الانسجة المناعية

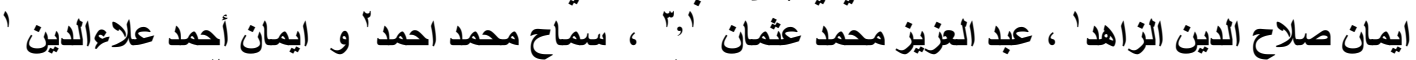

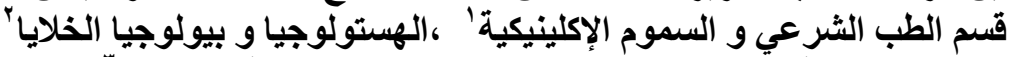 كلية الطب البثري - جامعة الزقازيق- مصر و مركز الخبرة القضائية والبحوثَ" الجبل الأخضر ليبيا}

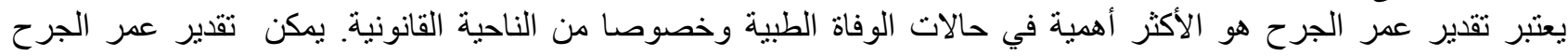

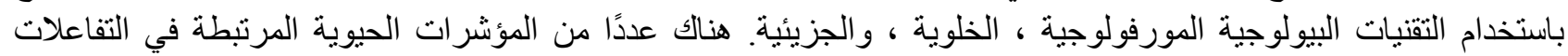

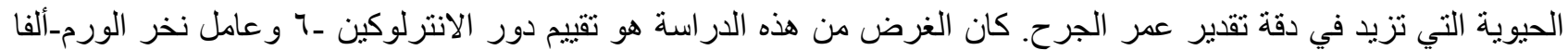

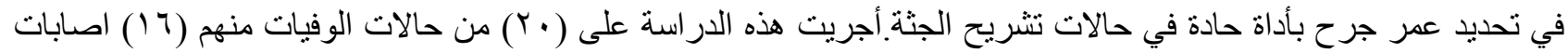

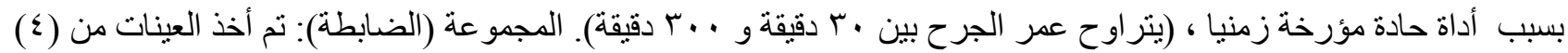

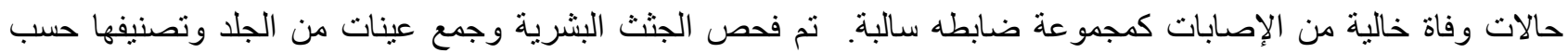

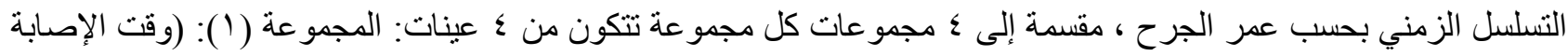

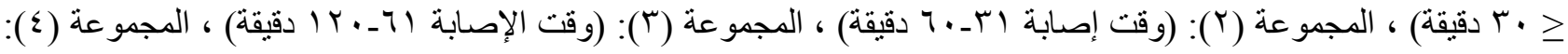

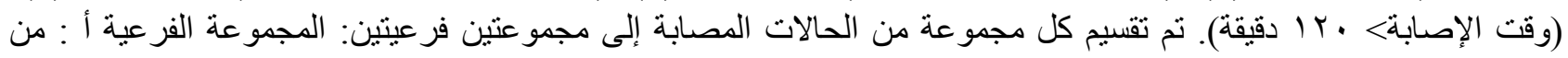

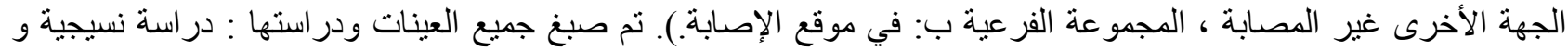

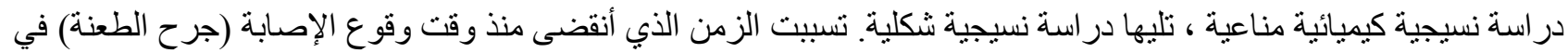

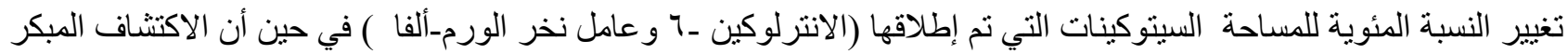

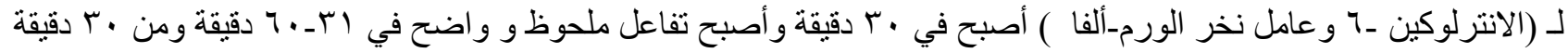

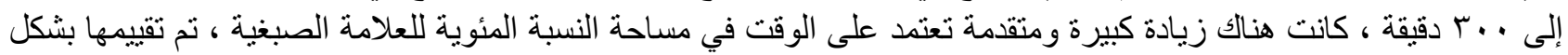

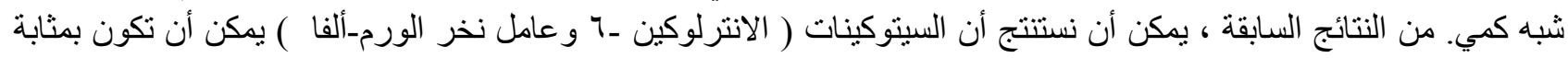

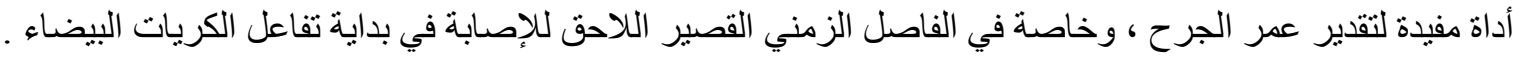

